\title{
Wogonoside alleviates inflammation induced by traumatic spinal cord injury by suppressing NF- $\kappa B$ and NLRP3 inflammasome activation
}

\author{
YONGLIN ZHU $^{1 *}$, HANZHONG ZHU $^{2 *}$, ZHAOJIE WANG ${ }^{1}$, FENGGUANG GAO $^{1}$, \\ JINGSHENG WANG $^{1}$ and WENQIANG ZHANG ${ }^{3}$
}

${ }^{1}$ Department of Orthopedics, Yantai Affiliated Hospital of Binzhou Medical University, Yantai, Shandong 264001;
${ }^{2}$ Department of Orthopedics, Chengwu People's Hospital, Heze, Shandong 274200; ${ }^{3}$ Department of Orthopedics,
Shandong Qianfoshan Hospital Affiliated to Shandong University, Jinan, Shandong 250014, P.R. China

Received October 11, 2015; Accepted April 13, 2017

DOI: $10.3892 /$ etm.2017.4904

\begin{abstract}
Wogonoside possesses anti-oxidative, anti-inflammatory, anti-allergy and anti-tumor properties. The aim of the present study was to evaluate whether wogonoside alleviates spinal cord injury (SCI)-induced inflammation via nuclear factor (NF)- $\mathrm{B}$ and nucleotide-binding oligomerization domain-like receptor family pyrin domain containing 3 (NLRP3) inflammasome activation. Sprague-Dawley rats were positioned in the jaws of a calibrated aneurysm clip with a closing pressure of $55 \mathrm{~g}$. The jaws were placed on the dorsal and ventral surfaces of the spinal cord and left in place for $1 \mathrm{~min}$. SCI rats were treated with 12,25 and $50 \mathrm{mg} / \mathrm{kg}$ wogonoside. Following this, the locomotor function was assessed using the Basso Beattie Bresnahan scale. The water content of the spinal cord was measured, tumor necrosis factor- $\alpha$ (TNF- $\alpha$ ), interleukin (IL)-1 $\beta$ and IL-6 levels were assessed and western blot analysis was performed to evaluate the expressions of NF- $\mathrm{kB}$ and NLRP3. Wogonoside was demonstrated to significantly ameliorate the SCI-induced reduction in Basso Beattie Bresnahan score $(\mathrm{P}<0.01)$ and significantly reduce the water content of the spinal cord in rats with SCI-induced inflammation $(\mathrm{P}<0.01)$. Results also indicated that treatment with wogonoside significantly reduced the levels of IL-1 $\beta$, TNF- $\alpha$ and IL-6 in rats with SCI-induced inflammation $(\mathrm{P}<0.01)$, potentially via the phosphorylation of $\mathrm{NF}-\kappa \mathrm{B}$ inhibitor $\alpha$. Furthermore, treatment with wogonoside
\end{abstract}

Correspondence to: Dr Wenqiang Zhang, Department of Orthopedics, Shandong Qianfoshan Hospital Affiliated to Shandong University, 16766 Jingshi Road, Jinan, Shandong 250014, P.R. China E-mail: wenqiangzhang5838@163.com

*Contributed equally

Key words: wogonoside, traumatic spinal cord injury, inflammation, nuclear factor- $\kappa \mathrm{B}$, nucleotide-binding oligomerization domain-like receptor family pyrin domain containing 3 inhibited the expressions of toll-like receptor 4, NLRP3 and caspase-1 protein in SCI model rats $(\mathrm{P}<0.01)$. In conclusion, the results of the present study suggest that wogonoside alleviates SCI-induced inflammation by suppressing NF-kB and NLRP3 inflammasome activation.

\section{Introduction}

Spinal cord injury (SCI) is a common type of trauma and cause of disability in China (1). The underlying mechanisms that cause secondary neuron injury following primary spinal cord injury are complex (2). It has been reported that experimental pharmacological agents are unable to act on multiple injury mechanisms at the same time, and inhibition of secondary injuries while ignoring their favorable aspects to the body, such as pain reduction and inflammation inhibition, may cause detrimental side-effects (3). Consequently, there is currently a lack of effective and safe clinical treatments for SCI.

SCI typically induces severe pathological nerve damage with limited functional recovery (4). The initial mechanical injury may destroy neurons and neuroglia, while even greater destructive effects are caused by delayed secondary pathological damage (5). Secondary injury may manifest as neuron and/or glial cell apoptosis, increased permeability of the blood-spinal cord barrier and a complicated neuro-inflammatory response, which may endure for months or years after injury (6).

Wogonoside (Fig. 1) has been reported to possess extensive pharmacological activities. In addition to anti-inflammatory, anti-allergy, anti-viral and antipyretic properties, recent studies have demonstrated that wogonoside possesses anti-oxidative and anti-tumor effects, along with cardiovascular protective effects $(7,8)$. Wogonoside is derived from Scutellaria baicalensis, and has exhibited efficacy as an antithrombotic, antihypertensive and antitumor therapeutic, and in the treatment of coronary heart disease (9). The aim of the present study was to determine whether wogonoside alleviated inflammation induced by activation of nuclear factor (NF)- $\kappa \mathrm{B}$ and the nucleotide-binding oligomerization domain-like receptor family pyrin domain containing 3 (NLRP3) inflammasome in an SCI rat model. 


\section{Materials and methods}

Animals and surgery. Adult male Sprague-Dawley (SD; age, 9-11 weeks; $\mathrm{n}=50$ ) rats weighing 230-250 g were obtained from the Animal Resource Center of the Yantai Affiliated Hospital of Binzhou Medical University (Yantai, China) for use in the present study. Rats were housed at an ambient temperature of $22 \pm 1^{\circ} \mathrm{C}$ under a 12 -h light/dark cycle, and $50-70 \%$ relative humidity. Pellet rat chow and tap water were available ad libitum. A rat model of SCI was induced as described previously (10). Briefly, rats were anesthetized intravenous injection (i.v.) with $35 \mathrm{mg} / \mathrm{kg}$ pentobarbital (all from Sigma-Aldrich; Merck KGaA, Darmstadt, Germany.) and underwent a laminectomy, during which the T8 and T9 vertebral peduncles were removed. The jaws of a calibrated aneurysm clip with a closing pressure of $55 \mathrm{~g}$ were placed on the dorsal and ventral surfaces of the spinal cord and left in place for $1 \mathrm{~min}$ to induce SCI. All experimental procedures were approved by the Ethics Committee of the Yantai Affiliated Hospital of Binzhou Medical University.

Experimental groups and procedures. All SD rats were underwent SCI surgery and were randomly divided into four groups: i) Control group (control; $n=10$ ), which underwent sham surgery (the operational area was exposed but no trauma was induced) and were administered with physiological saline (1 ml/kg, i.p.); ii) SCI model group (SCI model; $\mathrm{n}=10$ ), which underwent SCI surgery and were administered with physiological saline ( $1 \mathrm{ml} / \mathrm{kg}$, i.p.); iii) $12 \mathrm{mg} / \mathrm{kg}$ wogonoside group $(\mathrm{n}=10)$, administered with $12 \mathrm{mg} / \mathrm{kg}$ wogonoside (i.p.) for 10 days; iv) $25 \mathrm{mg} / \mathrm{kg}$ wogonoside group $(\mathrm{n}=10)$, administered with $25 \mathrm{mg} / \mathrm{kg}$ wogonoside (i.p.) for 10 days; and v) $50 \mathrm{mg} / \mathrm{kg}$ wogonoside group ( $\mathrm{n}=10)$, administered with $50 \mathrm{mg} / \mathrm{kg}$ wogonoside for 10 days (i.p.; Sigma-Aldrich; Merck KGaA).

Evaluation of locomotor function. Locomotor function was assessed by two researchers, using the Basso Beattie Bresnahan (BBB) locomotor rating scale, as described previously (11). A score of 0 indicates complete paralysis and a score of 21 indicates normal locomotion.

Evaluation of spinal cord contusion volume after SCI. Rats were sacrificed using decapitation following treatment with wogonoside (day 10) under anesthesia $(35 \mathrm{mg} / \mathrm{kg}$ pentobarbital). Spinal cord contusions were assessed by calculating the water content of the spinal cord. Injured spinal cords were dried at $-80^{\circ} \mathrm{C}$ for $48 \mathrm{~h}$ and the volume of spinal cord contusions was calculated using the following formula: Water content of spinal cord $(\%)=($ wet weight - dry weight $) /$ wet weight $\mathrm{x} 100$.

Evaluation of serum oxidative stress and inflammation. Blood (500 $\mu \mathrm{l})$ was harvested and serum was collected after centrifugation at $2,000 \mathrm{x}$ for $10 \mathrm{~min}$ at $4^{\circ} \mathrm{C}$. Serum tumor necrosis factor (TNF)- $\alpha$, interleukin (IL)-1 $\beta$ and IL-6 levels were analyzed using respective commercial immunoassay kits (cat. no. RTA00, RLB00 and R6000B, respectively; R\&D Systems, Inc., Minneapolis, MN, USA), according to the manufacturer's protocol.

Western blot analysis. Following sacrifice, spinal cord tissues were harvested and homogenized in RIPA lysis buffer

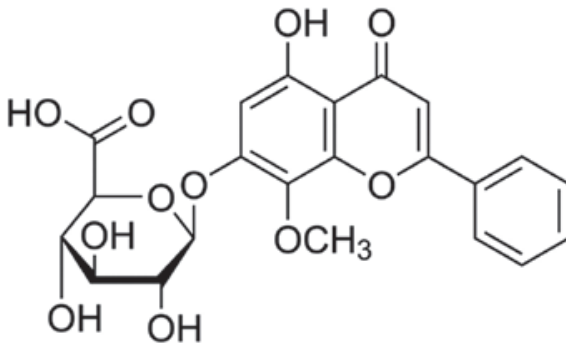

Figure 1. Chemical structure of wogonoside.

(Beyotime Institute of Biotechnology, Haimen China). The homogenate was centrifuged at $12,000 \mathrm{xg}$ for $20 \mathrm{~min}$ at $4^{\circ} \mathrm{C}$, and quantification of protein in the supernatant was performed using a bicinchoninic acid assay kit (Beyotime Institute of Biotechnology). A total of $50 \mu \mathrm{g}$ protein was loaded per lane, separated by $10 \%$ SDS-PAGE and electrotransferred onto nitrocellulose membranes. Membranes were blocked with $5 \%$ - skim milk powder in TBST for $1 \mathrm{~h}$ at $37^{\circ} \mathrm{C}$ and incubated with anti-TLR4 (sc-10741, 1:200; Santa Cruz Biotechnology, Inc.), anti-NF-кB p65 (cat. no. sc-109; 1:2,000; Santa Cruz Biotechnology, Inc.), anti-phosphorylated (p)-inhibitor of

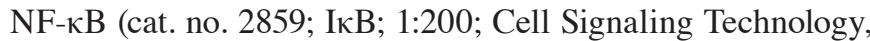
Inc.), anti-NLRP3 (cat. no. sc-66846; 1:300; Santa Cruz Biotechnology, Inc.), anti-caspase-1 (cat. no. sc-514; 1:300; Santa Cruz Biotechnology, Inc.) and anti- $\beta$-actin (cat. no. sc-7210; 1:500; Sangon Biotech Co., Ltd., Shanghai, China) at $4^{\circ} \mathrm{C}$ overnight. Membranes were subsequently incubated with secondary horseradish peroxidase-conjugated goat anti-rabbit antibody (cat. no. 14708; 1:5,000; Cell Signaling Technology, Inc.) at $37^{\circ} \mathrm{C}$ for $1 \mathrm{~h}$. The optical densities of immunopositive bands were visualized with BeyoECL Star (Beyotime Institute of Biotechnology) and determined using GeneTools software, version 4.1 (Synoptics, Ltd., Cambridge, UK).

Statistical analysis. All data are presented as the mean \pm standard deviation, assessed using SPSS, version 17.0 (SPSS, Inc., Chicago, IL, UA). Wilcoxon signed-rank tests were performed to evaluate differences in between the injured and control groups. $\mathrm{P}<0.05$ was considered to indicate a statistically significant difference.

\section{Results}

Wogonoside improves BBB score in rats with SCI-induced inflammation. BBB scores were calculated to analyze the effect of wogonoside on SCI-induced inflammation in rats. The BBB scores of rats in the SCI model group were significantly reduced compared with the control group $(\mathrm{P}<0.01$; Fig. 2$)$. Treatment with $12.5 \mathrm{mg} / \mathrm{kg}$ wogonoside for 10 days significantly alleviated the SCI-induced reduction in BBB score $(\mathrm{P}<0.01)$, as did treatment with 25 or $50 \mathrm{mg} / \mathrm{kg}$ wogonoside for 5 days or more $(\mathrm{P}<0.01$; Fig. 2$)$.

Wogonoside reduces the volume of spinal cord contusions in rats with SCI-induced inflammation. The volume of spinal cord contusions in rats with SCI-induced inflammation was assessed, and was observed to be significantly increased when compared with controls ( $\mathrm{P}<0.01$; Fig. 3 ). In turn, treatment with 


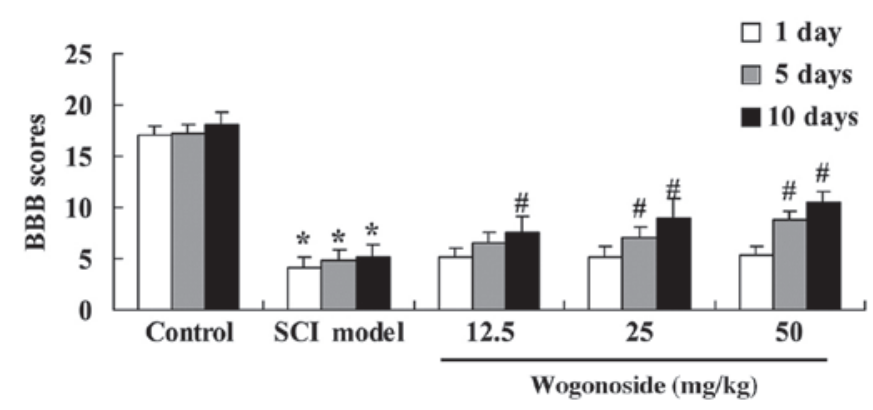

Figure 2. Wogonoside improves BBB score in SCI model rats. " $\mathrm{P}<0.01$ vs. control group; ${ }^{\text {P }}<0.01$ vs. SCI model group. BBB, Basso Beattie Bresnahan; $\mathrm{SCI}$, spinal cord injury.

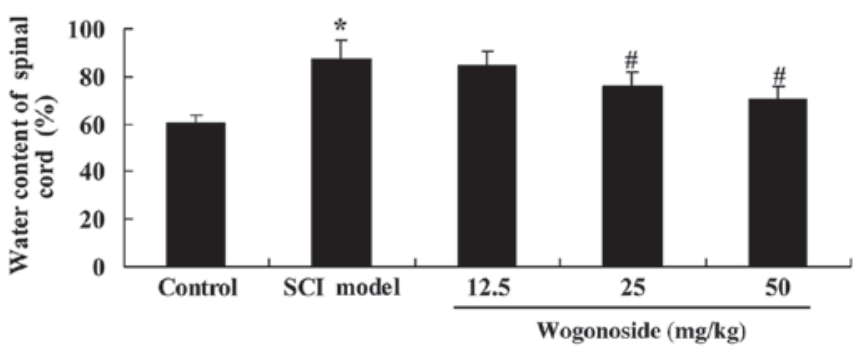

Figure 3. Wogonoside reduces the volume of SCI-induced contusions in rats. ${ }^{*} \mathrm{P}<0.01$ vs. control group; ${ }^{*} \mathrm{P}<0.01$ vs. SCI model group. SCI, spinal cord injury.

25 or $50 \mathrm{mg} / \mathrm{kg}$ wogonoside significantly reduced the increased volume of spinal cord contusions in SCI rats $(\mathrm{P}<0.01$; Fig. 3$)$.

Wogonoside suppresses SCI-induced upregulation of IL-1 $\beta$, $T N F-\alpha$ and IL- 6 in rats. To further elucidate the anti-inflammatory effects of wogonoside, ELISA was performed to measure the levels of IL- $1 \beta$, TNF- $\alpha$ and IL-6 in SCI model rats. IL- $1 \beta$, TNF- $\alpha$ and IL- 6 were significantly upregulated in the SCI model group when compared with the control group $(\mathrm{P}<0.01$; Fig. 4). No significant differences were observed in the levels of inflammatory cytokines between the $12.5 \mathrm{mg} / \mathrm{kg}$ wogonoside and model groups; however, treatment with 25 or $50 \mathrm{mg} / \mathrm{kg}$ wogonoside significantly reduced the levels of IL- $1 \beta$, TNF- $\alpha$ and IL-6 compared with the model group $(\mathrm{P}<0.01$; Fig. 4).

Wogonoside alleviates $N F-\kappa B$ and NLRP3 overexpression, and increases the activation of $I \kappa B$ expression in SCI model rats. Western blotting was used to evaluate the effect of wogonoside

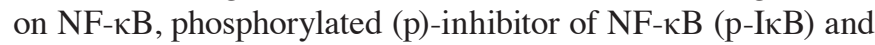
NLRP3 expression (Fig. 5A). A significant increase in the protein expression of NF- $\mathrm{KB}$ and NLRP3, and inhibition of $\mathrm{p}$-I $\kappa \mathrm{B}$ expression were observed in the SCI model group when compared with the control group ( $\mathrm{P}<0.01$; Fig. 5B-D). Treatment with $12.5 \mathrm{mg} / \mathrm{kg}$ wogonoside had no significant effect, whereas 25 or $50 \mathrm{mg} / \mathrm{kg}$ wogonoside significantly reduced NF- $\mathrm{kB}$ and NLRP3 expression, and increased $\mathrm{p}-\mathrm{I} \kappa \mathrm{B}$ expression compared with the SCI model group $(\mathrm{P}<0.01$; Fig. 5B-D).

Wogonoside ameliorates caspase-1 and TLR4 overexpression in SCI model rats. The effect of wogonoside on caspase-1 expression in SCI rats was assessed using western blotting (Fig. 6A). SCI was demonstrated to significantly increase
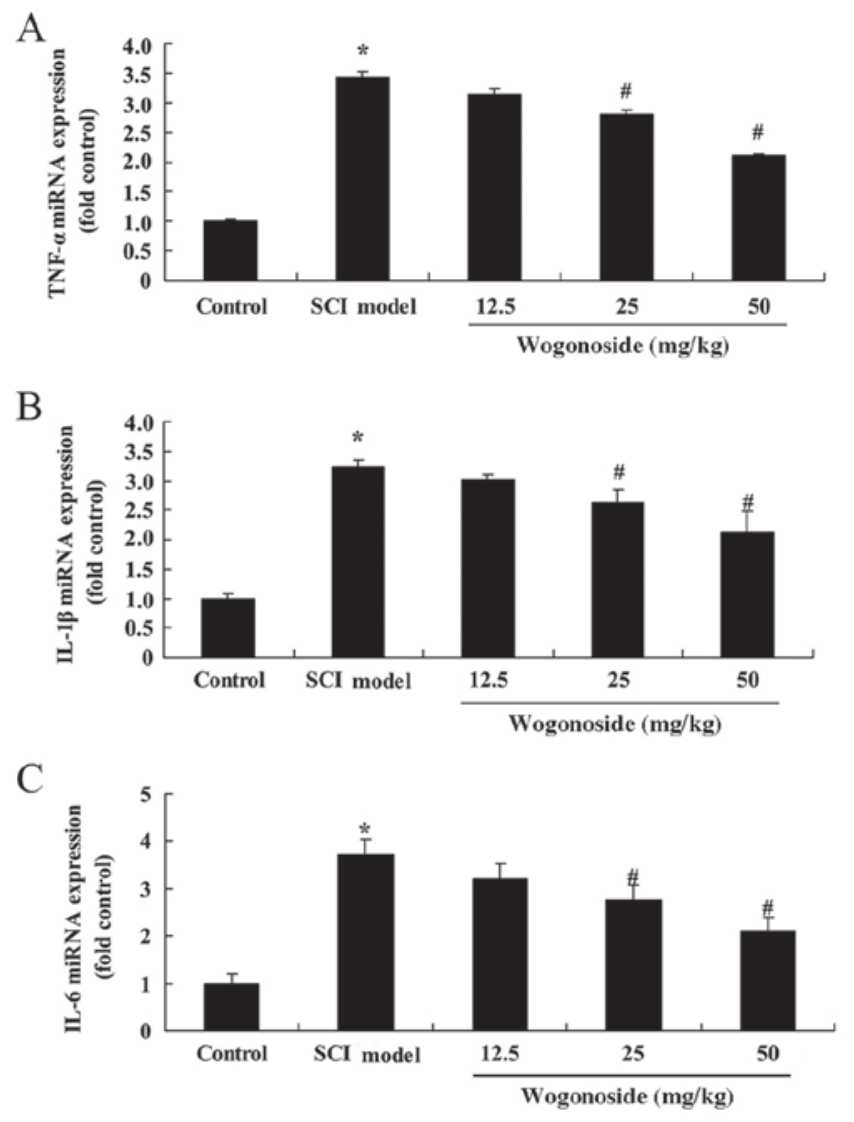

Figure 4. Wogonoside suppresses SCI-induced upregulation of (A) TNF- $\alpha$, (B) IL-1 $\beta$ and (C) IL-6 in rats. ${ }^{*} \mathrm{P}<0.01$ vs. control group; ${ }^{*} \mathrm{P}<0.01$ vs. SCI model group. SCI, spinal cord injury; IL, interleukin; TNF, tumor necrosis factor.

the protein expression of caspase- 1 and TLR4, relative to the control group $(\mathrm{P}<0.01$; Fig. $6 \mathrm{~B}$ and $\mathrm{C})$. Treatment with $12.5 \mathrm{mg} / \mathrm{kg}$ wogonoside induced no significant difference in caspase-1 or TLR4 expression, whereas 25 or $50 \mathrm{mg} / \mathrm{kg}$ wogonoside significantly reduced the levels of caspase- 1 in SCI rats $(\mathrm{P}<0.01$; Fig. $6 \mathrm{~B}$ and $\mathrm{C})$.

\section{Discussion}

SCI is a traumatic central nervous system injury, and frequently leads to varying degrees of anesthesia and loss of motor function in the limb below the plane of injury, making it a leading cause of disability in the field of orthopedics (12). Increasing urbanization has led to an increase in injuries caused by traffic accidents, falling accidents and professional accidents for engineers and construction workers (13). Over the last 10 years, the morbidity of SCI in China and other countries has increased (14). SCI-induced functional paralysis causes physiological and psychological trauma to patients, and is a cause of medical and economic stress for families and society (14). In the present study, treatment with wogonoside was demonstrated to significantly increase the BBB score and decrease the volume of spinal cord contusions in rats with SCI-induced inflammation.

Cytokines may be classified into two major types; proinflammatory factors and anti-inflammatory factors. Proinflammatory factors are expressed to a high-level in conditions of oxidative stress, which may further increase the level of oxidative stress (15). 
A

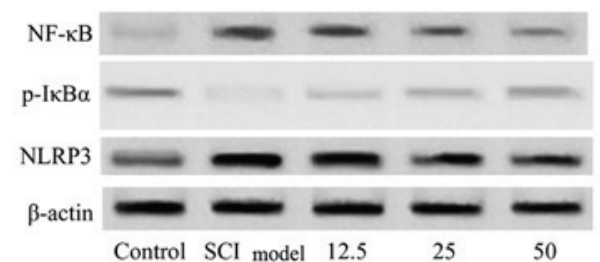

$\mathrm{C}$

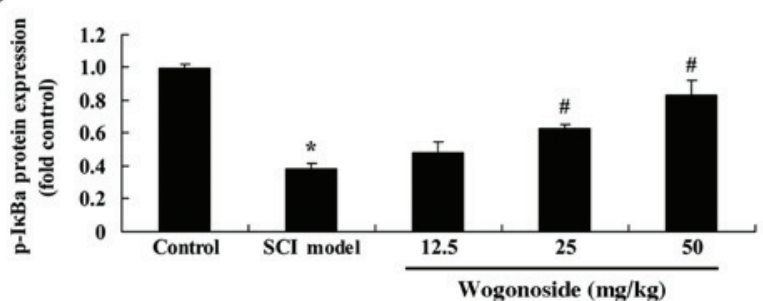

$\mathrm{B}$
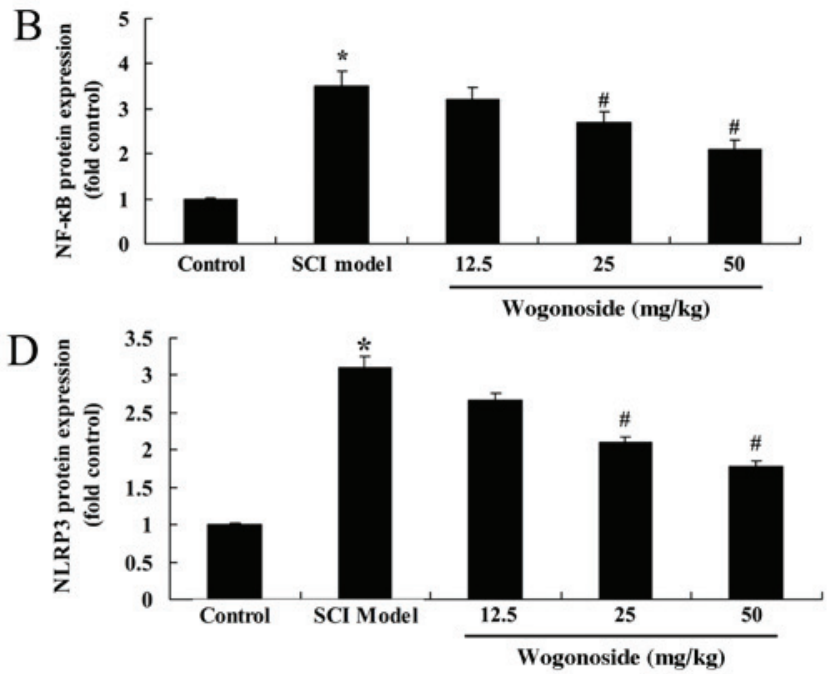

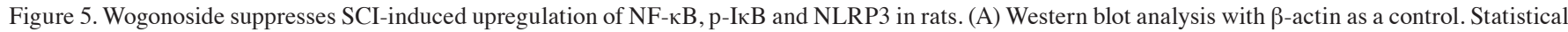
analysis of (B) NF- $\mathrm{B},(\mathrm{C}) \mathrm{p}-\mathrm{I} \kappa \mathrm{B}$ and (D) NLRP3 protein expression in an SCI rat model. ${ }^{*} \mathrm{P}<0.01$ vs. control group; ${ }^{\text {P }}<0.01$ vs. SCI model group. SCI, spinal cord injury; NF, nuclear factor; NF- $\kappa \mathrm{B}$, nuclear factor- $\kappa \mathrm{B}$; $\mathrm{p}-\mathrm{I} \kappa \mathrm{B}$; NLRP3, nucleotide-binding oligomerization domain-like receptor family pyrin domain containing 3 .

A

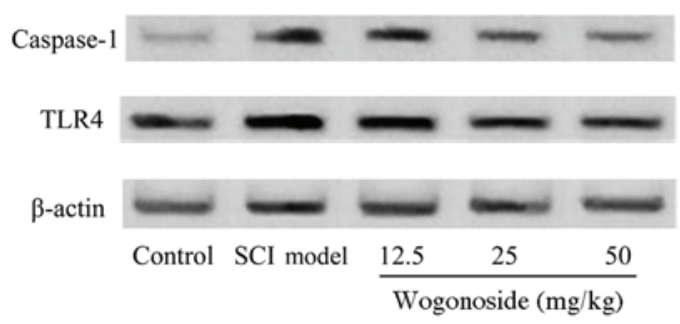

$\mathrm{B}$

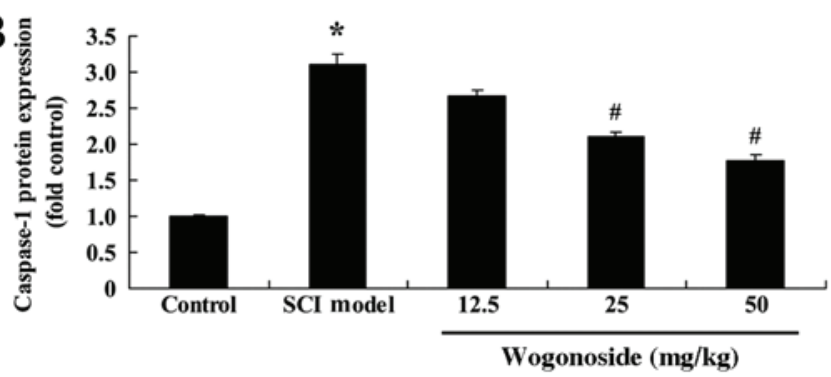

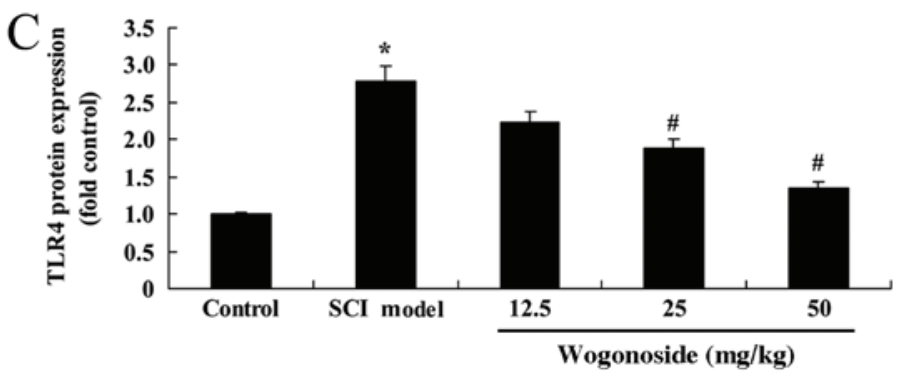

Figure 6. Wogonoside suppresses SCI-induced overexpression of caspase-1 and TLR4 in rats. (A) Western blotting and (B and C) statistical analysis of caspase-1 and TLR4 protein expression in an SCI rat model. ${ }^{*} \mathrm{P}<0.01$ vs. control group; ${ }^{*} \mathrm{P}<0.01$ vs. SCI model group. SCI, spinal cord injury.

During oxidative stress, the upregulated proinflammatory factors include TNF- $\alpha$, IL-1 $\beta$, IL-2, IL-6 and IL-12, and NF- $\kappa$ B is also activated $(16,17)$. In the present study, treatment with 25 or $50 \mathrm{mg} / \mathrm{kg}$ of wogonoside significantly inhibited the upregulation in IL-1 $\beta$, TNF- $\alpha$ and IL-6 in SCI model rats. Yang et al (18) suggested that wogonoside induces anti-inflammatory effects in RAW264.7 cells, which indicated that wogonoside possessed anti-inflammation effect in SCI.

Interactions between lipopolysaccharides (LPS) and TLR4 induce the activation of transcription factors, including $\mathrm{NF}-\kappa \mathrm{B}$ and activator protein-1, which ultimately induces the expression of proinflammatory and anti-inflammatory factors (19). NF- $\kappa \mathrm{B}$ is a multi-functional nuclear transcription factor, and is associated with the LPS-induced inflammatory response (19). In the cytoplasm, I $\kappa \mathrm{B}$ binds with inactive $\mathrm{NF}-\kappa \mathrm{B}$, which covers the nuclear localization sequence of NF- $\kappa \mathrm{B}$ and thus prevents the activation and nuclear translocation of NF- $\kappa$ B (20). I $\kappa$ B degradation is therefore required for the activation of NF- $\kappa \mathrm{B}$. IкB is regulated by $\mathrm{I} \kappa \mathrm{B}$ kinase, which catalyzes phosphorylation of the $42^{\prime}$ serine residue in I $\kappa \mathrm{B}$ as a signal for degradation, which induces rapid degradation of $\mathrm{I} \kappa \mathrm{B}$ (typically within several min) and exposes the nuclear localization sequence of NF- $\kappa \mathrm{B}(21)$. The nuclear localization sequence of $N F-\kappa B$ is disclosed and $N F-\kappa B$ is activated and translocated to nucleus (22). Once there, $N F-\kappa B$ binds with the $\kappa \mathrm{B}$ locus in the $\mathrm{NF}-\kappa \mathrm{B}$ reactive gene to regulate gene transcription and downstream cellular processes, including cell growth, differentiation, adhesion, apoptosis and the inflammatory response (22). Excessive phosphorylation of $\mathrm{I} \kappa \mathrm{B}$ results in a loss of $\mathrm{NF}-\kappa \mathrm{B}$ inhibition (23). In the present study, it was demonstrated that treatment with 25 or 
$50 \mathrm{mg} / \mathrm{kg}$ of wogonoside significantly inhibited inflammation through the suppression of $\mathrm{NF}-\kappa \mathrm{B} / \mathrm{I} \kappa \mathrm{B}$ in an SCI rat model. Similarly, Zhang et al (7) reported that wogonoside ameliorates LPS-induced acute lung injury in mice through the suppression of TLR4-mediated NF- $\mathrm{BB}$ signaling.

The NLRP3 inflammasome promotes the secretion of IL-1 $\beta$, IL-18 and IL-33, and the production of these factors is critical in the control of pathological infection (24). However, excessive cytokine production is harmful to the body (24), and therefore activation of the NLRP3 inflammasome must be strictly regulated to maintain hemostasis (25). Similarly, Sun et al (26) demonstrated that wogonoside protects against dextran sulfate sodium-induced colitis by suppressing NF- $\mathrm{B}$ and NLRP3 inflammasome activation in mice.

In conclusion, the present study demonstrated that wogonoside alleviated the reduced BBB scores and increased spinal cord contusion volume of SCI model rats. Furthermore, it was observed that wogonoside ameliorated inflammation via the $\mathrm{NF}-\kappa \mathrm{B} / \mathrm{I} \kappa \mathrm{B}$ and NLRP3/caspase-1/TLR4 pathways. The present study was limited as it only assessed the in vivo aspect, therefore in vitro or clinical models should be assessed in future studies. The results of the present study suggest that wogonoside is a potential novel treatment for SCI trauma, and may have clinical applications in ameliorating the associated inflammation.

\section{Acknowledgements}

This study was supported by the Pharmaceutical Health Science and Technology Development Program of Shandong Province (grant no. 2015WS0477).

\section{References}

1. Yalçın S and Ersöz M: Urodynamic findings, bladder emptying methods and therapeutic approaches in patients with upper lumbar and lower lumbar-sacral spinal cord injury. Neurol Sci 36: 2061-2065, 2015.

2. Pirouzmand F: Epidemiological trends of spine and spinal cord injuries in the largest Canadian adult trauma center from 1986 to 2006. J Neurosurg Spine 12: 131-140, 2010.

3. Werndle MC,Zoumprouli A, Sedgwick P and Papadopoulos MC: Variability in the treatment of acute spinal cord injury in the United Kingdom: Results of a national survey. J Neurotrauma 29: 880-888, 2012.

4. Zhang N, Yin Y, Xu SJ, Wu YP and Chen WS: Inflammation \& apoptosis in spinal cord injury. Indian J Med Res 135: 287-296, 2012.

5. Rosety-Rodriguez M, Camacho A, Rosety I, Fornieles G, Rosety MA, Diaz AJ, Bernardi M, Rosety M and Ordonez FJ: Low-grade systemic inflammation and leptin levels were improved by arm cranking exercise in adults with chronic spinal cord injury. Arch Phys Med Rehabil 95: 297-302, 2014.

6. Yuan YM and He C: The glial scar in spinal cord injury and repair. Neurosci Bull 29: 421-435, 2013.

7. Zhang L, Ren Y, Yang C, Guo Y, Zhang X, Hou G, Guo X, Sun N and Liu Y: Wogonoside ameliorates lipopolysaccharide-induced acute lung injury in mice. Inflammation 37: 2006-2012, 2014.

8. Wang Q, Wen R, Lin Q, Wang N, Lu P and Zhu X: Wogonoside shows antifibrotic effects in an experimental regression model of hepatic fibrosis. Dig Dis Sci 60: 3329-3339, 2015.
9. Li H, Hui H, Xu J, Yang H, Zhang X, Liu X, Zhou Y, Li Z, Guo Q and $\mathrm{Lu} \mathrm{N}$ : Wogonoside induces growth inhibition and cell cycle arrest via promoting the expression and binding activity of GATA-1 in chronic myelogenous leukemia cells. Arch Toxicol 90: 1507-1522, 2016.

10. Ravikumar R, Fugaccia I, Scheff SW, Geddes JW, Srinivasan C and Toborek M: Nicotine attenuates morphological deficits in a contusion model of spinal cord injury. J Neurotrauma 22: 240-251, 2005.

11. Basso DM, Beattie MS, Bresnahan JC, Anderson DK, Faden AI, Gruner JA, Holford TR, Hsu CY, Noble LJ, Nockels R, et al: MASCIS evaluation of open field locomotor scores: Effects of experience and teamwork on reliability. Multicenter Animal Spinal Cord Injury Study. J Neurotrauma 13: 343-359, 1996.

12. Zhang T, Liu H, Liu Z and Wang L: Acupuncture for neurogenic bladder due to spinal cord injury: A systematic review protocol. BMJ Open 4: e006249, 2014.

13. Neirinckx V, Cantinieaux D, Coste C, Rogister B, Franzen R and Wislet-Gendebien S: Concise review: Spinal cord injuries: How could adult mesenchymal and neural crest stem cells take up the challenge? Stem Cells 32: 829-843, 2014.

14. Curt A and Ellaway PH: Clinical neurophysiology in the prognosis and monitoring of traumatic spinal cord injury. Handb Clin Neurol 109: 63-75, 2012.

15. Evans CT, Hershow RC, Chin A, Foulis PR, Burns SP and Weaver FM: Bloodstream infections and setting of onset in persons with spinal cord injury and disorder. Spinal Cord 47: 610-615, 2009.

16. Heyninck K, Lahtela-Kakkonen M, Van der Veken P,Haegeman G and Vanden Berghe W: Withaferin A inhibits NF-kappaB activation by targeting cysteine 179 in IKK $\beta$. Biochem Pharmacol 91: 501-509, 2014.

17. Sakthivel KM and Guruvayoorappan C: Acacia ferruginea inhibits tumor progression by regulating inflammatory mediators-(TNF-a, iNOS, COX-2, IL-1 $\beta$, IL-6, IFN- $\gamma$, IL-2, GM-CSF) and pro-angiogenic growth factor-VEGF. Asian Pac J Cancer Prev 14: 3909-3919, 2013.

18. Yang YZ, Tang YZ and Liu YH: Wogonoside displays anti-inflammatory effects through modulating inflammatory mediator expression using RAW264.7 cells. J Ethnopharmacol 148: 271-276, 2013.

19. Yunusova T, Akhtar M and Poltoratsky V: Analysis of LPSinduced, NFאB-dependent interleukin-8 transcription in kidney embryonic cell line expressing TLR4 using luciferase assay. Methods Mol Biol 1172: 305-314, 2014.

20. Shifera AS: Protein-protein interactions involving IKKgamma (NEMO) that promote the activation of NF-kappaB. J Cell Physiol 223: 558-561, 2010.

21. Oeckinghaus A and Ghosh S: The NF-kappaB family of transcription factors and its regulation. Cold Spring Harb Perspect Biol 1: a000034, 2009.

22. Schuliga M: NF-kappaB signaling in chronic inflammatory airway disease. Biomolecules 5: 1266-1283, 2015.

23. Xie YF, Shu R, Jiang SY, Song ZC, Guo QM, Dong JC and Lin ZK: miRNA-146 negatively regulates the production of proinflammatory cytokines via NF- $\kappa \mathrm{B}$ signalling in human gingival fibroblasts. J Inflamm (Lond) 11: 38, 2014.

24. Cassel SL, Joly S and Sutterwala FS: The NLRP3 inflammasome: A sensor of immune danger signals. Semin Immunol 21: 194-198, 2009.

25. Butts B, Gary RA, Dunbar SB and Butler J: The importance of NLRP3 inflammasome in heart failure. J Card Fail 21: 586-593, 2015.

26. Sun Y, Zhao Y, Yao J, Zhao L, Wu Z, Wang Y, D, Miao H, Guo Q and Lu N: Wogonoside protects against dextran sulfate sodium-induced experimental colitis in mice by inhibiting NF-kappaB and NLRP3 inflammasome activation. Biochem Pharmacol 94: 142-154, 2015. 